\title{
Н.Н. Шпильная
}

\section{НЕЙТРАЛИЗАЦИЯ КАК ДЕРИВАЦИОННЫЙ МЕХАНИЗМ ГЕНЕЗИСА ДИАЛОГИЧЕСКОГО ТЕКСТА}

\begin{abstract}
В статье рассматривается один из деривационных механизмов генезиса диалогического текста - нейтрализачия. Под нейтрализацией понимается прочесс совпадения различных парадигматических вариантов диалогического текста в том или ином члене текстовой оппозиции. Результат нейтрализации - диалогический текст, представленный в речевой цеепи одним из комбинаторных вариантов, совпадающим с тем или иным членом текстовой оппозиции. Обосновывается, что нейтрализация диалогических текстов обусловлена свойством асимметричного дуализма языкового знака. Ключевые слова: диалог, диалогический текст, деривация, нейтрализация, производныцй текст.
\end{abstract}

Статья вписывается в ряд исследований, посвященных проблеме генезиса диалогического текста. Несмотря на то, что данная проблема уже давно осознана в языкознании, она, к сожалению, не имеет окончательного решения. В современной лингвистике доминирующим является подход, согласно которому динамика диалогического текста объясняется новизной высказывания, коррелирующей с функциональной позицией адресанта как участника коммуникации ([1-7] и др.). При этом полагается, что диалогический текст как комбинаторно-семантическая единица языка актуализируется в условиях асимметричной коммуникативной ситуации.

Антроподинамическая модель генезиса диалогического текста имеет ряд ограничений, связанных с тем, что в поле зрения лингвистов оказывается интерактивное значение диалогического текста как речевого произведения, представленного в речевой цепи двумя и более высказываниями. Полагается, что диалогический текст есть результат согласования иллокутивных установок и общего когнитивного фона (фреймов, сценариев и пр.) носителей языка. Однако данная модель не объясняет явление диалогической цитации (термин Н.Д. Арутюновой), т.е. прагматической выводимости означаемого диалогического текста из его означающего. Онтологический статус данного явления подтверждается возможностью создания диалогического текста вследствие прагматической выводимости его означаемого из нескольких означающих, нейтрализующихся в «будущем» означающем этого означаемого. К примеру, реплики типа «Согласна / согласен с вами (с ними, с аудиторией) и пр.», «Не согласен / не согласна с вами (с ними, с аудиторией) и пр.», встречающиеся как в устной, так и в письменной диалогической (полилогической) коммуникации, возникают вследствие нейтрализации других высказываний, служащих объектом деривации. Как нам представляется, объяснять процесс образования подобных высказываний только согласованием иллокутивных установок носителей языка - это значит упростить процесс текстооб- 
разования и роль тех механизмов, которые принимают участие в актах генезиса текста. То обстоятельство, что данные речевые высказывания обычно остаются за пределами исследовательского внимания, можно объяснить как субъективными, так и объективными факторами. С одной стороны, при объяснении процесса генезиса текста лингвисты, как правило, ограничиваются описанием реплик, связанных регрессивной связью (субъективный фактор). Иными словами, деривация текста рассматривается в отношении двух текстов, один из которых является текстом-объектом (текстом-основой), а другой - текстом-целью (производным текстом). С другой стороны, лингвисты зачастую лишены возможности фиксировать текстовые синтагмы, состоящие из нескольких речевых произведений, созданных на базе некоторого, исходного для них; особенно это касается устной речи (объективный фактор). Между тем, как представляется, само наличие явления нейтрализации доказывает, с одной стороны, факт существования языковых единиц как самостоятельных образований, выполняющих смыслоразличительную (референтативную) функцию, а с другой - факт суппозиционного обеспечения синтагматических отношений в системе языка. Способность диалогического текста одновременно быть соотнесенным с несколькими диалогическими текстами в речевой цепи означает, что в актах его образования принимает участие не только содержание, но и форма высказываний, служащих для них суппозицией (подробнее см. ниже).

В работах, выполненных нами ранее [9, 10], подробно обосновывается, что генезис диалогического текста есть результат актуализации деривационного механизма диалогической цитации, определяющего прагматический фокус выводимости означаемого диалогического текста из его означающего (способ структурной организации диалогического текста) и опосредующего акты его производства / воспроизводства по трем моделям: модели согласования, модели контраста и модели примыкания ${ }^{1}$. При этом полагается, что множественность моделей деривации диалогического текста как производнопрагматической единицы языка обусловлена функциональной позицией носителя языка, выступающего в актах коммуникации в статусе отвечающего, выражающего в процессе производства текста не новизну содержания, а новизну факта высказывания. В таком случае планом выражения диалогического текста является монологическое высказывание. Как следствие, модель согласования актуализирует диалогическую позицию согласования, модель контраста - диалогическую позицию несогласия и модель примыкания - нейтральную диалогическую позицию субъекта высказывания.

Однако наблюдения над генезисом и функционированием диалогического текста позволяют говорить о том, что наряду с механизмом диалогической

\footnotetext{
${ }^{1}$ В лингвистике уже предпринимались попытки описания текста как результата актуализации деривационных механизмов. Традиционно считается, что генезис текста обусловлен актуализацией деривационного механизма трансформации, реализуемого в процессах его контаминации и компрессии [11-13]. Однако в указанных работах генезис текста рассматривается как номинативный процесс, а сам текст - как производно-номинативная единица (монологический текст), имеющая своим референтом внеязыковой контекст и выполняющая референтативную функцию. Очевидно, что подобный подход к представлению текста не учитывает реальные условия его существования и функционирования, обусловленные его адаптированностью к ситуации диалога, предшествующей феномену языка как таковому.
} 
цитации генезис диалогического текста может быть опосредован механизмом нейтрализации, определяющим выводимость означаемого диалогического текста из нескольких означающих, имеющих различный прагматический фокус. Иными словами, механизм нейтрализации обусловливает совпадение нескольких диалогических текстов, имеющих тот или иной способ структурной организации, в одном варианте, внутренняя форма которого может совпадать / не совпадать с формой исходных для него вариантов.

Как известно, явление нейтрализации было осмыслено в лингвистике в работах Н.С. Трубецкого, понимающего под нейтрализацией процесс и результат интеграции различных фонем в одном аллофоне, совпадающем с перцептивно и сигнификативно сильной позицией первого или второго члена оппозиции. Нейтрализация будет наблюдаться и в том случае, если фонемы совпадут в третьем звуке, не имеющем корреляции с указанной ранее сильной позицией фонемы. При этом показателем нейтрализации фонем является невозможность выполнения ими сигнификативных (смыслоразличительных) функций. Ср.: «Во всех этих случаях <..> звук, который появляется в позиции нейтрализации, представляет собой своего рода комбинаторный вариант как первого, так и второго члена оппозиции. Хотя такие случаи замещения архифонемы звуком, который не совпадает полностью ни с одним из членов оппозиции, весьма часты, они встречаются все же реже, чем те случаи, когда звук, выступающий в позиции нейтрализации, оказывается более или менее сходным с определенным членом оппозиции в релевантной позиции» [14].

Далее основные положения теории нейтрализации были спроецированы не только на единицы плана выражения, но и на единицы плана содержания, как следствие, становится возможным говорить о нейтрализации семантических (в том числе семантико-грамматических) оппозиций. В этом случае нередко нейтрализация рассматривается как частный случай проявления омонимии, при которой наблюдается тождество формы языковых единиц при наличии противопоставлений на уровне их содержания (набора сем). Так или иначе, говоря о нейтрализации плана выражения и / или плана содержания языковых единиц, лингвисты преимущественно рассматривают нейтрализацию тех или иных парадигматических вариантов языковой единицы, находящихся в сигнификативно слабой позиции в синтагме. К примеру, наличие явления таронимии, описываемого в лексикологии, доказывает, что актуализация лексических единиц сопровождается выбором парадигматического варианта, основанным на некой исходной лексической единице, служащей суппозицией для воспроизводимой лексемы [15]. Совпадение в синтагматической цепи вариантов парадигматических оппозиций в одном варианте как раз и опосредуется механизмом нейтрализации, имеющим деривационную природу.

Исследование генезиса и функционирования диалогических текстов позволяет спроецировать основные положения теории нейтрализации на акты его производства / воспроизводства. Признавая дискуссионный характер положения об изоморфизме актов функционирования разноуровневых единиц языка, мы, однако, полагаем, что данный тезис отражает «объективное положение дел» в том смысле, что является не методологической установкой исследователя, а результатом, следствием анализа эмпирических данных. 
Далее говоря о текстовой подсистеме языка, мы полагаем, что она образуется трехчленной привативной оппозицией, два члена которой являются маркированными, а один - немаркированным. Маркированными членами текстовой оппозиции являются диалогические тексты, воспроизводимые по моделям согласования или контраста, а немаркированным членом оппозиции является диалогический текст, производимый по модели примыкания. При этом оппозиция диалогических текстов отражает прагматико-эпидигматические отношения в системе языка. В речевой цепи наблюдается процесс комбинаторного соподчинения диалогических текстов, обусловленный парадигматическими отношениями, имеющими место в текстовой подсистеме языка. Как следствие, речевой поток можно представить как линейную последовательность диалогических текстов, образующих парадигматические варианты текстовых оппозиций по типу модель согласования - модель контраста, модель примыкания - модель согласования, модель контраста модель примыкания и пр. При этом в речевой цепи текстовые оппозиции могут нейтрализоваться. Это означает, что производимый диалогический текст возникает как результат совпадения различных парадигматических вариантов текстообразовательных моделей в том или ином члене трехчленной текстовой оппозиции. Результатом нейтрализации парадигматических вариантов диалогических текстов является диалогический текст, субъект которого адресует свою диалогическую позицию субъектам предшествующих ему диалогических текстов (и, конечно, другим носителям языка, которые имеют возможность познакомиться с этим текстом). Иными словами, результатом нейтрализации может быть диалогический текст, представленный в речевой цепи одним из комбинаторных вариантов, совпадающим с тем или иным членом текстовой оппозиции.

Нейтрализация диалогических текстов связана со сменой деривационного шага, формированием нового коммуникативного замысла носителя языка. При этом смена деривационного шага, с одной стороны, приводит к нейтрализации деривационных вариантов, их конвергенции, а с другой - к формированию нового коммуникативного замысла, который воплощается в деривационных вариантах, возникающих вследствие дивергенции «нового» текстаосновы (подробнее об этом см. в [10]). Механизм нейтрализации диалогических текстов различен ${ }^{1}$. Специфика текстовой нейтрализации заключается в том, что ее результат зависит от того, какие парадигматические варианты диалогического текста становятся источником генезиса «нового» текста. Так,

\footnotetext{
${ }^{1}$ Особенности генезиса диалогического текста как следствия актуализации деривационного механизма нейтрализации иллюстрируются на примере анализа 202 диалогических текстов, размещенных в сети Интернет по адресу http://news.ngs.ru /more/1253828/ и объединенных общей макротемой «Переходы в метро: гопники вместо цветов». В качестве текста-основы рассматривается текст новостной статьи «Переходы в метро: гопники вместо цветов», а диалогические тексты, представляющие собой комментарии к нему, интерпретируются как его деривационные варианты (ДВТ). При этом в исследовании каждый из ДВТ квалифицируется как самостоятельный диалогический текст (текстцель), созданный на основе того или иного текста-основы, и в то же время как вариант диалогического текста-основы. Основное содержание текста-основы может быть представлено в форме нейтральной модусной пропозиции: Губернатор Новосибирской области Василий Юрченко распорядился до 1 августа очистить все вестибюли новосибирского метрополитена от торговых киосков в иелях обеспечения безопасности жителей города от терактов. Все тексты приводятся с сохранением авторской орфографии и пунктуации.
} 
с одной стороны, нейтрализации могут быть подвержены диалогические тексты, производимые по разным моделям - модели согласования, модели примыкания и модели контраста. А с другой стороны, нейтрализации могут быть подвержены однотипные диалогические тексты, т.е. диалогические тексты, производимые по одной и той же модели. Если в первом случае производимый в результате нейтрализации диалогический текст создается по модели примыкания, то во втором случае - либо по модели согласования, либо по модели контраста, либо по модели примыкания ${ }^{1}$. Асимметричный характер распределения парадигматических вариантов диалогических текстов в позиции нейтрализации может быть объяснен свойством асимметричного дуализма языкового знака, определяющего функционирование языковых единиц. Применительно к ситуации диалога речь идет о выражении разных форм (означающих) в одном означаемом, означающее которого аналогично означающему немаркированного члена текстовой оппозиции, и о выражении одной формы в означаемом, означающее которого находится в отношениях синонимии или антонимии с означающими тех или иных членов текстовой оппозиции.

Рассмотрим примеры, иллюстрирующие процесс нейтрализации разных означающих в одном означаемом, означающее которого аналогично означающему немаркированного члена текстовой оппозиции.

\section{ДВТ-9 \\ хожу пешком ${ }^{\text {гость }}$}

10 июл 2013 00: 34

У меня глупый вопрос и 1 одна наивная надежда:

1. кто знает, деньги от арендь куда уходят? Муниципалитету или метрополитену?

2. Оставили бы киоски печати (газеты, журналы)

ДВТ-10

\section{GLOBUS}

\section{0 июл 2013 00: 37}

Будем теперь ходить поздними вечерами по пустынным длинным мрачным вестибюлям., сжимая в страхе газовый баллончик в потной ладони.. бррр..

\section{ДВТ-11}

\section{Mytia65}

\section{0 июл 2013 00: 38}

Мне нравится Юрченко - достраивает некоторые объекты городские, которые мэр не тянет, и вообще, заставил шевелиться всех подчиненных. Но с метро он перегнул, через колено решает опять, как с проездом в свое время. Киоски по одной стороне перехода не мешают безопасности, мне кажется, и нужны многим покупателям. Хотя у губернатора информации больше от фсб, а если так, то много чего надо ликвидировать в приступе очередной кампании. Я бы в другую сторону посмотрел - наоборот, стро-

\footnotetext{
${ }^{1}$ Тезис, согласно которому производимый в результате нейтрализации однотипных текстов диалогический текст может быть создан по модели примыкания, основан на наших рассуждениях. Анализируемый материал не позволяет подтвердить или опровергнуть данное положение.
} 
ить подземные переходы в проблемных местах и сдавать их в аренду чтобы уменьшить расходы. Городецкому понравится, это конёк мэрии - мьл вам место, а вы нам фонтан, или автовокзал (ха-ха), или деньги. Главное чтобы инвестор не бросил объект, и тогда горожане скажут спасибо за хорошую работу.

\section{ДВТ-37}

\section{Roman_nsk}

\section{0 июл 2013 08: 26}

Что такого изенного продают в переходах метро, чего нельзя купить в других местах? Зачем эти киоски в метро? С 2008 года не был в метро и мне ни разу не понадобилось туда спуститься чтобы что-то купить. Я думаю и другие люди переживут.

\section{ДВТ-65}

\section{Манометр}

\section{0 июл 2013 09: 22}

Давно пора убрать эти уродливые киоски, особенно, в переходе на Маркса. Там ходить страшно! Везде пьяные, сльиен мат.

\section{ДВТ-105 \\ Влад $\boldsymbol{Я}^{\text {гость }}$}

\section{0 июл 2013 11: 07}

Бредовое решение, которое не прибавит популярности губернатору, поскольку на метро все ездят и все иногда что-то да покупают: газеты, сигареты, воду, изветы итп. Я вот покупал машинки журнальные для коллекции, где их теперь ловить?

\section{ДВТ-115}

\section{Максим гость}

\section{0 июл 2013 11: 56}

Мнения разделились. Пора референдум проводить по поводу разрешения, запрещения торговли в метро. Но в некоторых узких переходах киоски реально мешают, когда людей много идет, это факт. Если уж так много сторонников запрета, то хотя бы убрать киоски из узких мест. Оставить только там, где достаточно пространства для свобоного прохода в чась пик.

ДВТ-115 создан по модели примыкания, предполагающей выражение нейтральной диалогической позиции субъектом высказывания. Нейтральный модус субъекта диалогического текста обнаруживается в его желании разобраться в ситуации, предложить оптимальный вариант решения проблемной ситуации: он поддерживает как сторонников запрета торговли в метро, так и тех, кто возражает против решения губернатора. Ср.: то хотя бы убрать киоски из узких мест. Оставить только там, где достаточно пространства для свобоного прохода в часы пик.

Диалогическая позиция пользователя адресована всем субъектам диалогических текстов, которые послужили источником генезиса анализируемого текста. При этом, как видим, последние созданы по разным моделям: модели примыкания (ДВТ-9, ДВТ-11), модели согласования (ДВТ-37, ДВТ-65) и модели контраста (ДВТ-105). Ср. с высказыванием: Мнения разделились. 
Далее приведем примеры диалогических текстов, иллюстрирующих процесс и результат нейтрализации текстов, созданных по одной и той же модели. Как мы уже отмечали, нейтрализация одноструктурных текстов обнаруживается в совпадении их означающих в означаемом, означающее которого находится в отношениях синонимии или антонимии с означающими крайних (маркированных) членов текстовой оппозиции. При этом возможны следующие варианты реализации механизма нейтрализации в текстовой синтагме:

1) диалогические тексты, созданные по модели контраста, нейтрализуются в диалогическом тексте, созданном по модели согласования;

2) диалогические тексты, созданные по модели согласования, нейтрализуются в диалогическом тексте, созданном по модели контраста;

3) диалогические тексты, созданные по модели контраста, нейтрализуются в диалогическом тексте, созданном по модели контраста;

4) диалогические тексты, созданные по модели согласования, нейтрализуются в диалогическом тексте, созданном по модели согласования (данный вариант нейтрализации диалогических текстов мы не можем проиллюстрировать, так как он не представлен в анализируемом нами материале).

Сначала рассмотрим нейтрализацию текстов, созданных по модели контраста, в диалогическом тексте, производимом по модели согласования (1) или по модели контраста (3).

\section{ДВТ-3}

\section{Работник Павлик}

\section{0 июл 2013 00: 17}

Бред!!! Какая антитеррористическая безопасность? Наша «честно выбранная» власть готова придумать любые оправдания для подавления мелкого бизнеса! Ну кому помешали газеты, изветы, трусы и носки? Какая от них может быть опасность? Если они уйдут в торговые центры, то там они обонкротятся, $m \kappa$, продавая газеты и ияеть, они не заработают даже на аренду... В переходах метро, на мой взгляд, более или менее ещче нормально все организовано!

\section{ДВТ-6}

Нитка гость

\section{0 июл 2013 00: 22}

А ведь так удобно было, торопишься на работу, покупаешь какую-нибудь мелочь в метро: открытку, книжку, ручку, сок, булочку, колготки и отксерить можно и ключи сделать. Губернатор в метро не ездит, ему этого не понять (( Антинародное нововведение, а если еще и цены на проезд поднимутся, так вообще!

\section{ДВТ-48}

\section{наивный}

\section{0 июл 2013 08: 53}

как же власть далека о народа. поездил бы губернатор с мэром в метро, а не рассуждал бы абстрактно 
ДВТ-80

Евгения ${ }^{\text {гость }}$

10 июл 2013 09: 42

Абсолютно согласна с большинством! Вижу только минусы в отсутствии киосков в переходах:

1) по-быстренькому ничего не купишь, ни шоколадку, ни колготки;

2) идти по пустому тоннелю очень страшно и не приятно, особенно в вечерние часы!

3) люди теряют работу, деньги!

Боже, помоги нашим властям опомниться, свернуть с этого пути!

Губернатор Юрченко! Я вас до последних событий очень уважала, но это уже чересчур!

ДВТ-96

$\ddot{\mathbf{E}} \mathbf{k}$

10 июл 2013 10: 25

Какие пессимистичные сегодня коментаторы))) Зато места больше станет, а толкотни меньше. Шоколадку купить и в ларьке можно, круглосуточных киосков по линии метро пока хватает как и магазинов с колготками, носками, батарейками и цветами. А точки с ворованными телефонами и пиратскими дисками вообще работают благодаря серьезному недосмотру полиции, и привлекают в метрополитен все тех же гопников.

Рассмотрим ДВТ-80 и ДВТ-96. Данные деривационные варианты созданы вследствие конвергенции указанных выше ДВТ, предполагающей их нейтрализацию, т.е. совпадение в одном диалогическом тексте. Однако ДВТ-80 создан по модели согласования, а ДВТ-96 - по модели контраста. Так, субъект ДВТ-80 поддерживает тех пользователей, которые не согласны с губернатором Юрченко, а субъект ДВТ-96, наоборот, не поддерживает тех пользователей, которые не согласны с губернатором Новосибирской области. При этом исходные деривационные варианты текста и производимые в результате нейтрализации диалогические тексты вступают в антонимические отношения друг с другом.

Рассмотрев особенности нейтрализации диалогических текстов, созданных по модели контраста, охарактеризуем процесс производства диалогического текста, созданного по модели контраста и возникающего в результате нейтрализации диалогических текстов, созданных по модели согласования (2).

\section{ДВТ-2}

Антон гость

10 июл 2013 00: 10

Всё правильно делают. Долой барыг, ханыг и спекулянтов из метро. Иногда бывает пройти тяжело в часы пик, когда идет поток людей по переходу, а часть людей останавливается у киосков, матерю торгашей и протискиваюсь. 


\section{ДВТ-34}

vaz2108@ngs.ru

10 июл 2013 08: 09

Давно пора разогнать эту всю мелкую торговлю дорогим и некачественнылм товаром. А то реально как в отстальх странах, по всей стране какие то киосочки, ларечки, микрорынки... Все это не украшает город.

\section{ДВТ-108 \\ PzVIH}

\section{0 июл 2013 11: 15}

Думаю, что большинство радуюшихся по поводу этого «гениального» решения гр. юрченко просто завидует работягам-предпринимателям.

ДВТ-108 создан по модели контраста, так как субъект диалогического текста не согласен с теми пользователями, которые поддерживают решение губернатора: по поводу «гениального» решения гр. юрченко. Иными словами, ДВТ представляет собой ответ всем пользователям, которые одобряют решение губернатора. При этом исходные деривационные варианты текста и производимый диалогический текст (ДВТ-108) вступают в антонимические отношения друг с другом, так как первые созданы по модели согласования, а последний - по модели контраста. Заметим также, что по отношению к исходному для всех них тексту нейтрализуемые ДВТ и производимый ДВТ будут являться антонимами, так как выражают разные диалогические позиции носителей языка.

Таким образом, в статье рассмотрены особенности реализации деривационного механизма нейтрализации, обусловливающего генезис и функционирование диалогических текстов, их комбинаторные чередования в речевой цепи.

В работе показано, что механизм нейтрализации диалогических текстов различен; он обусловлен свойством асимметричного дуализма языкового знака. Если нейтрализации подвержены диалогические тексты, производимые по разным моделям - модели согласования, модели примыкания и модели контраста по отношению к исходному для всех них тексту, то производимый в результате нейтрализации диалогический текст создается по модели примыкания. А если нейтрализации подвержены однотипные диалогические тексты, т.е. диалогические тексты, производимые по одной и той же модели, то в этом случае диалогический текст создается либо по модели согласования, либо по модели контраста. При этом диалогические тексты, созданные по модели контраста, могут нейтрализоваться в диалогическом тексте, созданном либо по модели согласования, либо по модели контраста, а диалогические тексты, созданные по модели согласования, могут нейтрализоваться в диалогическом тексте, созданном по модели контраста или по модели согласования (последний вариант реализации механизма нейтрализации не представлен в анализируемом материале).

Признание нейтрализации одним из деривационных механизмов генезиса диалогического текста позволяет говорить об изоморфизме актов функционирования разноуровневых единиц языка, служащих частным случаем их генезиса. 


\section{Лumepamypa}

1. Падучева Е.В. Прагматические аспекты связности диалога // Изв. АН СССР. Сер. лит. и яз. 1982. Т. 41, № 4. С. 305-313.

2. Грайс Г.П. Логика и речевое общение // Новое в зарубежной лингвистике. М., 1985. Вып. 16. С. 217-238.

3. Дейк T.A. Когнитивные модели этнических ситуаций // Язык. Познание. Коммуникация; пер. с англ. / сост. В.В. Петрова; под ред. В.И. Герасимова; вступ. ст. Ю.Н. Караулова, В.В. Петрова. М., 1989. С. 161-189.

4. Баранов А.Н., Крейдлин Г.Е. Иллокутивное вынуждение в структуре диалога // Вопр. языкознания. 1992. № 2. С. 84-99.

5. Колокольцева T.Н. Специфические коммуникативные единицы диалогической речи. Волгоград, 2001. $260 \mathrm{c}$.

6. Кибрик А.А. Анализ дискурса в когнитивной перспективе: дис. в виде науч. докл., составленного на основе опубликованных работ, представленная к защите на соискание ученой степени д-ра филол. наук. М., 2003. 90 с.

7. Борисова И.Н. Русский разговорный диалог: Структура и динамика. М., 2007. 320 с.

8. Арутюнова Н.Д. Диалогическая цитация (к проблеме чужой речи) // Вопр. языкознания. 1986. № 1. C. 50-64.

9. Шиильная Н.Н. Диалогическая цитация как деривационный механизм текстообразования. Производный текст как диалогический текст // Вопр. когнитивной лингвистики. 2015. № 4 (045). С. 101-112.

10. Шпильная Н.Н. Диалогический текст как компонент непрерывного деривационноинтерпретационного процесса // Вестн. Том. гос. ун-та. Филология. 2015. № 4 (36). С. 56-70.

11. Мурзин Л.Н. О деривационных механизмах текстообразования // Теоретические аспекты деривации. Пермь, 1982. С. 20-22.

12. Чувакин А.А. Деривационные отношения как тип межтекстовых отношений (к предмету текстодериватологии) // Актуальные проблемы дериватологии, мотивологии, лексикографии. Томск, 1998. С. 23-24.

13. Мельник Н.В. Деривационное функционирование русского текста: лингвоцентрический и персоноцентрический аспекты: дис. ... д-ра филол. наук. Кемерово, 2011. 403 с.

14. Трубеикой Н.С. Основы фонологии. Логическая классификация смыслоразличительных оппозиций. URL: http://genhis.philol.msu.ru/article_130.shtml (дата обращения: 11.06.2016).

15. Мандрикова Г.М. Таронимия как лингвистический объект. Новосибирск: Изд-во НГТУ, 2011. $150 \mathrm{c}$.

\section{NEUTRALISATION AS A DERIVATIONAL MECHANISM OF THE DIALOGICAL TEXT GENESIS}

Vestnik Tomskogo gosudarstvennogo universiteta. Filologiya - Tomsk State University Journal of Philology. 2017. 46. 84-94. DOI: 10.17223/19986645/46/7

Nadezhda N. Shpilnaya, Altai State Pedagogical University (Barnaul, Russian Federation). E-mail: venata85@mail.ru

Keywords: dialog, dialogical text, derivation, neutralisation, derivative text.

This study gives grounds to the fact that genesis of the dialogical text is mediated by neutralization of the derivational nature. Neutralization refers to the process of convergence of dialogical texts of a certain structural organization method. Neutralization of dialogical texts is performed by means of addressing a derivational option of a dialogical text to a set of derivational options and their alignment according to the terms of the recipient's image. It is attributed to the change of the derivational step, generation of a new communication concept by the native speaker which is embodied in derivational options arising from the divergence of the "new" base text. The phenomenon of neutralization of dialogical texts proves the existence of dialogical texts as independent units performing a distinctive (reference) function, on the one hand, and as a suppositive base of syntagmatic relations within the language system, on the other hand.

It is shown that dialogic texts neutralization mechanism is diverse; it is due to the asymmetric dualism property of the linguistic sign. If dialogical texts produced by different models (concord model, adjunction model, models of contrast with respect to the original text for all of them) are neutralised, 
the resulting dialogical text is created by the adjunction model. If dialogical texts are exposed to the same type of neutralization (texts produced by the same model), the dialogical text is created by the concord model or by the contrast model. Dialogical texts created by the contrast model can be neutralized in a dialogical text created by concord or contrast models; dialogical texts created by the concord model can be neutralized in a dialogical text created by contrast or concord models (the latter embodiment of the neutralizing mechanism is not present in the test material).

Features of the dialogical text genesis as a result of actualization of the derivational mechanism of neutralization is exemplified by 202 dialogical texts taken from the web-site http://news.ngs.ru/more/1253828/. The texts are united by the common macro-topic "Underground Crosswalks: Hoodlums instead of Flower Vendors". The text of the news article "Underground Crosswalks: Hoodlums instead of Flower Vendors" is taken as the base text, while the dialogical texts that comment it are interpreted as its derivational options. Herewith, the study qualifies each derivational option of the text both as an independent dialogical text (target text) generated on the basis of the base text and as a [derivative] option of the dialogical base text at the same time.

\section{References}

1. Paducheva, E.V. (1982) Pragmaticheskie aspekty svyaznosti dialoga [Pragmatic aspects of the connectivity of dialogue]. Izvestiya AN SSSR. Ser. lit. i yazyka. 41:4. pp. 305-313.

2. Grays, G.P. (1985) Logika i rechevoe obshchenie [Logic and speech communication]. Novoe v zarubezhnoy lingvistike.16. pp. 217-238.

3. Dijk, T.A. (1989) Kognitivnye modeli etnicheskikh situatsiy [Cognitive models of ethnic situations]. Translated from English. In: Gerasimov, V.I. (ed.) Yazyk. Poznanie. Kommunikatsiya [Language. Cognition. Communication]. Moscow: Progress.

4. Baranov, A.N. \& Kreydlin, G.E. (1992) Illokutivnoe vynuzhdenie v strukture dialoga [Illocutionary compulsion in the structure of dialogue]. Voprosy yazykoznaniya. 2. pp. 84-99.

5. Kolokol'tseva, T.N. (2001) Spetsificheskie kommunikativnye edinitsy dialogicheskoy rechi [Specific communicative units of dialogical speech]. Volgograd: Peremena.

6. Kibrik. A.A. (2003) Analiz diskursa v kognitivnoy perspektive [Analysis of discourse in the cognitive perspective]. Philology Dr. Diss. Moscow.

7. Borisova, I.N. (2007) Russkiy razgovornyy dialog: Struktura i dinamika [Russian colloquial dialogue: Structure and dynamics]. Moscow: Librokom.

8. Arutyunova, N.D. (1986) Dialogicheskaya tsitatsiya (k probleme chuzhoy rechi) [Dialogue citation (to the problem of someone else's speech)]. Voprosy yazykoznaniya. 1. pp. 50-64.

9. Shpil'naya, N.N. (2015) Dialogicheskaya tsitatsiya kak derivatsionnyy mekhanizm tekstoobrazovaniya. Proizvodnyy tekst kak dialogicheskiy tekst [Dialogue citation as a derivational mechanism of text formation]. Voprosy kognitivnoy lingvistiki. 4 (045). pp. 101-112.

10. Shpil'naya, N.N. (2015) Dialogical text as component of the derivative interpretative process. Vestnik Tomskogo gosudarstvennogo universiteta. Filologiya - Tomsk State University Journal of Philology. 4 (36). pp. 56-70. (In Russian)

11. Murzin, L.N. (1982) O derivatsionnykh mekhanizmakh tekstoobrazovaniya [On derivational mechanisms of text formation]. In: Teoreticheskie aspekty derivatsii [Theoretical aspects of derivation]. Perm: Perm State University.

12. Chuvakin, A.A. (1998) Derivatsionnye otnosheniya kak tip mezhtekstovykh otnosheniy (k predmetu tekstoderivatologii) [Derivational relations as a type of intertextual relations (on the subject of text-derivatology)]. Aktual'nye problemy derivatologii, motivologii, leksikografii [Topical issues of derivatology, motiology, lexicography]. Proceedings of the conference. Tomsk: Tomsk State University. pp. 23-24. (In Russian)

13. Mel'nik, N.V. (2011) Derivatsionnoe funktsionirovanie russkogo teksta: lingvotsentricheskiy $i$ personotsentricheskiy aspekty [Derivational functioning of the Russian text: linguocentric and personcentric aspects]. Philology Dr. Diss. Kemerovo.

14. Trubetskoy, N.S. (2007) Osnovy fonologii. Logicheskaya klassifikatsiya smyslorazlichitel'nykh oppozitsiy [Fundamentals of phonology. Logical classification of meaningdifferentiating oppositions]. [Online] Available from: http://genhis.philol.msu.ru/article_130.shtml. (Accessed 11th June 2016).

15. Mandrikova, G.M. (2011) Taronimiya kak lingvisticheskiy ob"ekt [Taronomy as a linguistic object]. Novosibirsk: Novosibirsk State Technical University. 